REVISTA ECONOMÍA

Vol. 67, N.o I05 (mayo 2015), 75-95.

\title{
LA INVERSIÓN DE CHINA EN AMÉRICA LATINA. EL CASO DE LOS RECURSOS NATURALES
}

\author{
MARIO ÁVILA, NATALY TORRES, PABLO TREJO \\ Facultad Latinoamericana de Ciencias Sociales, sede Ecuador
}

Recepción manuscrito: 23 de diciembre de 2014

Aceptación versión final: 15 de abril de 2015

\begin{abstract}
RESUMEN Este artículo analiza la importancia de China como nuevo actor estratégico dentro del sector extractivo latinoamericano. Se demuestra que existe una focalización de su inversión extranjera directa hacia los países con ventajas comparativas en recursos naturales, principalmente mineros y petroleros. Además, existen dos características propias de las inversiones chinas que le diferencian de las tradicionales: a) las empresas chinas han acaparado grandes proyectos extractivos en América Latina, y b) la inversión extranjera en los Estados latinoamericanos se ve condicionada a préstamos respaldados con commodities, principalmente petróleo.
\end{abstract}

palabras ClAVE Commodities, petróleo, minería, China, América Latina, inversión extranjera directa.

ABSTRACT This article analizes the importance of China as a new strategic actor in the extractive sector in Latin America. It is demonstrated that there is a concentration of the foreign direct investment of China to the countries with comparative advantages of natural resources, mainly mining and oil industries. In addition, there are two proper characteristics of the chinese investments which differentiate from the traditional investments: a) the chinese companies have captured large extractive projects in Latin America, and b) the foreign investment in the Latin American states is conditioned to credits supported by commodities, mainly oil.

KEYwords Commodities, oil, mining, China, Latin America, foreign direct investment.

CODIFICACIÓN JEL L71, L72, N25, N56, F21.

\section{INTRODUCCIÓN}

La geopolítica mundial está viviendo cambios trascendentales en las últimas décadas. A nivel internacional, se escuchan frecuentemente discursos políticos y sociales que avizoran a nuevos aliados comerciales provenientes de economías emergentes. Se destaca el gran crecimiento económico de China que ha transformado las clásicas relaciones sociopolíticas y económicas en el mundo y de manera particular en América Latina. China está generando un nuevo orden global gracias a su crecimiento económico basado, entre otros, a la producción de manufacturas, oferta de tecnología, de bienes y servicios y, principalmente, en explotación, procesamiento y 
comercialización de recursos naturales. Esto ha desencadenado que muchas empresas extractivas migren hacia zonas ricas en reservas minerales y de hidrocarburos, entre las cuales figura América Latina.

El motivo principal de la inversión de las empresas chinas ha sido la necesidad de asegurar la provisión de ciertas materias primas consideradas estratégicas para garantizar su crecimiento económico y, para lo cual, Latinoamérica desempeña un papel geopolítico privilegiado (Downs, 2011 en CAF, 2013). La presencia significativa de inversiones chinas en la región se cataloga como un proceso relativamente nuevo. Sin embargo, la tendencia de focalización sectorial y la participación mayoritaria de las empresas estatales tanto en la participación de proyectos extractivos como en el diseño de políticas de inversión y financiamiento, constituyen importantes elementos de análisis.

Con estos antecedentes, esta investigación pretende analizar la importancia de China como nuevo actor en el sector extractivo de América Latina. A partir del estudio de las inversiones suscitadas en el sector de los recursos naturales y las políticas de los gobiernos centrales, se identifica los cambios y/o continuidades en la administración de los sectores extractivos en América Latina. Para ello, este trabajo aborda tópicos como las reservas de recursos existentes en la región, la inversión extranjera directa (IED) de China en América Latina y el rol que tienen sus empresas. Finalmente se analiza los condicionamientos de los préstamos del gigante asiático a los Estados latinoamericanos cuyas garantías de pago se respaldan en materias primas.

\section{AMÉRICA LATINA COMO RESERVA DE RECURSOS NATURALES}

El incremento de la economía y el consumo energético mundial han provocado que a nivel global exista un significativo aumento de la demanda de minerales, combustibles fósiles y materias primas en general. Esto ha desencadenado que las fronteras extractivas en los países productores avancen hacia zonas más remotas, con mayor dificultad de accesibilidad y donde la explotación de los recursos se torna aún más sensible. Este fenómeno se repite en varios países latinoamericanos cuyas economías se han especializado en explotar recursos naturales: Brasil, Chile, Bolivia, Perú, Venezuela, Ecuador, entre otros.

América Latina ha mantenido una tradición primario-exportadora y esto ha generado impactos económicos ambiguos para la región pues, por un lado, la renta generada ayudó al sostenimiento de las economías de los países, pero también muchos de estos sufrieron el incremento sustancial del endeudamiento externo, por aceptar créditos internacionales para financiar sus necesidades nacionales y explotar sus recursos.

Latinoamérica es en la actualidad una región de gran interés a nivel mundial como fuente de materias primas. Así, los principales países industrializados apuntan sus inversiones hacia la región debido, entre otros factores, al alto suministro de recursos naturales. Por ejemplo, según Bruckmann (2012), Estados Unidos importa desde América Latina el 93\% de estroncio, $84 \%$ de la bauxita, $66 \%$ de litio, $61 \%$ de fluorita, 59\% de plata, $56 \%$ de renio, $54 \%$ de estaño, entre otros. Por ello, la autora afirma que la región tiene gran capacidad de decisión sobre el precio internacional de los commodities, y concluye que se debe promover una 
política latinoamericana que «establezca los precios internacionales no basándose en la especulación del mercado financiero, sino en criterios como las reservas de minerales de la región, en sus tasas de agotamiento y en las tendencias al consumo global marcadas por los ciclos tecnológicos» (Bruckmann, 2012, p. 50).

En términos de reservas, la región mantiene importantes yacimientos de recursos naturales, principalmente de minerales estratégicos y petróleo; este último proveniente en su mayoría de las reservas hidrocarburíferas de Venezuela. En este sentido, varios estudios (Bruckmann, 2012; BP, 2013; OPEP, 2013) han destacado la relevancia latinoamericana por sus reservas para abastecer la demanda internacional. Por ejemplo, América Latina abarca especial importancia mundial en minerales considerados como estratégicos, como niobio (98\%), litio (86\%), renio (54\%) o cobre (48\%) (ver Figura 1).

Así mismo, en virtud de sus reservas de petróleo, la región se catapulta como la segunda zona de mayor interés a nivel global. Según BP (2013), Latinoamérica tiene el 19,7\% de las reservas petrolíferas probadas del mundo, solo superadas por las de Medio Oriente, cuyo valor asciende al 48,4\% del total del planeta (ver Figura 2). Los países con mayores reservas probadas en América Latina son, en estricto orden, Venezuela, Brasil y Ecuador (ver Tabla 1). Además de las reservas de petróleo, la región cuenta también con reservas de otros combustibles de origen fósil como el gas y el carbón, sin que estos recursos representen cifras significativas a nivel mundial (ver Figuras 3 y 4 ).

El ascenso económico de China ha llevado a incrementar su consumo de recursos naturales como petróleo, cobre y carbón (Flavin y Gardner, 2006) y con ello ha transformado el sistema económico mundial y por ende las relaciones con el resto del mundo, principalmente con los países ricos en materias primas. Así, en los últimos años, China se ha convertido en un destacado importador y consumidor de los minerales de América Latina. Sin embargo, también existen acuerdos «estratégicos» que convierten a esta región en el centro de su actividad. Estos acuerdos implican importantes tratados de producción e inversión en minería y petróleo, pero también en infraestructura, productos agroindustriales e incluso en la construcción de viviendas. De esta manera, China ya no es solo un gran comprador de minerales o de petróleo, sino que está contribuyendo también a la explotación e industrialización de esos recursos mediante sus inversiones directas en la región, desplazando a los inversores tradicionales en el sector extractivo como es el caso de empresas de Estados Unidos y Canadá.

\section{¿SON LOS RECURSOS NATURALES DE AMÉRICA LATINA UN ATRACTIVO DE INVERSIÓN PARA CHINA?}

En las últimas décadas, los flujos de Inversión Extranjera Directa (IED) en América Latina y el Caribe han mantenido un crecimiento sostenido salvo las fluctuaciones experimentadas en el periodo 2000-2002 — producto de la crisis de la deuda en Argentina, la crisis brasilera y la breve recesión de la economía estadounidense- y en el 2009 debido a la crisis financiera internacional. No obstante, los gobiernos han aplicado medidas para atraer nuevas inversiones y retener las existentes. 
Figura 1. Reservas de minerales estratégicos de América Latina, China y Estados Unidos con respecto a las reservas mundiales 2009 (en \%).

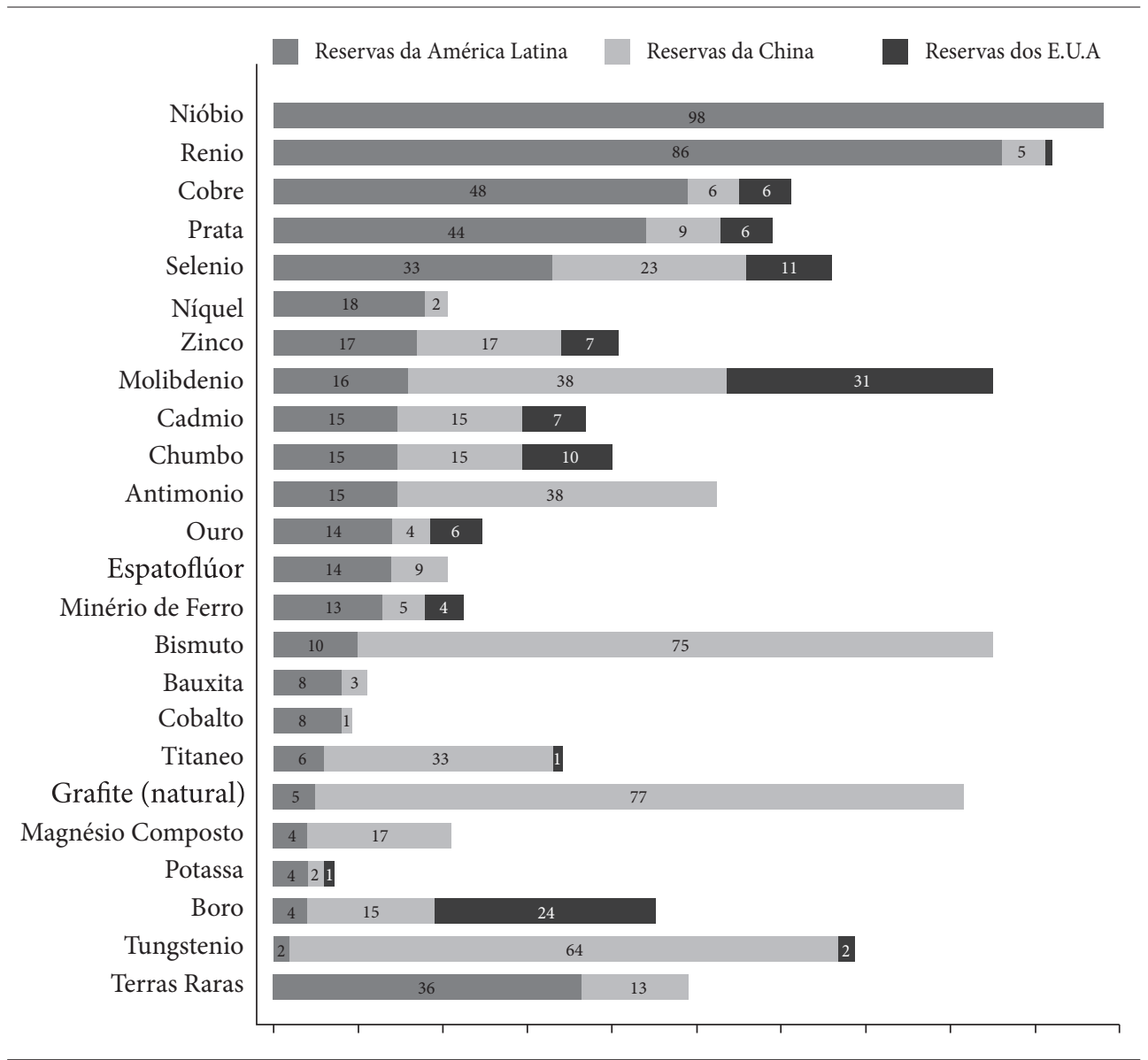

Fuente: Bruckmann (2012) con información de USGS.

Según datos presentados por la CEPAL, durante toda la década de los noventa, la IED ha mostrado una tendencia creciente hasta 1999 donde se registró un máximo de 93521 millones de dólares antes de caer a 73753 millones en 2001, seguido de una fuerte reducción en el periodo 2002 (56308 millones) y 2003 (46938 millones). Posteriormente, los flujos de IED iniciaron nuevamente un ritmo acelerado de crecimiento debido a la recuperación de la economía mundial y los altos precios de los recursos naturales. Este crecimiento se interrumpió momentáneamente en el 2009 por la crisis financiera mundial. En el 2010, la IED se ubicó en 124368 millones de dólares que representan un incremento del 49,9\% con respecto al año anterior. En el 2011, América Latina y el Caribe fue la región del mundo donde más crecieron las entradas de IED alcanzando una participación mundial del 10\% y en el 2012 se obtuvo un récord de inversión: 173361 millones de dólares. «En 2013, la inversión extranjera directa (IED) en América 
Figura 2. Evolución de las reservas probadas de petróleo del mundo entre 1992 y 2012. Datos expresados en porcentaje (\%) por región.

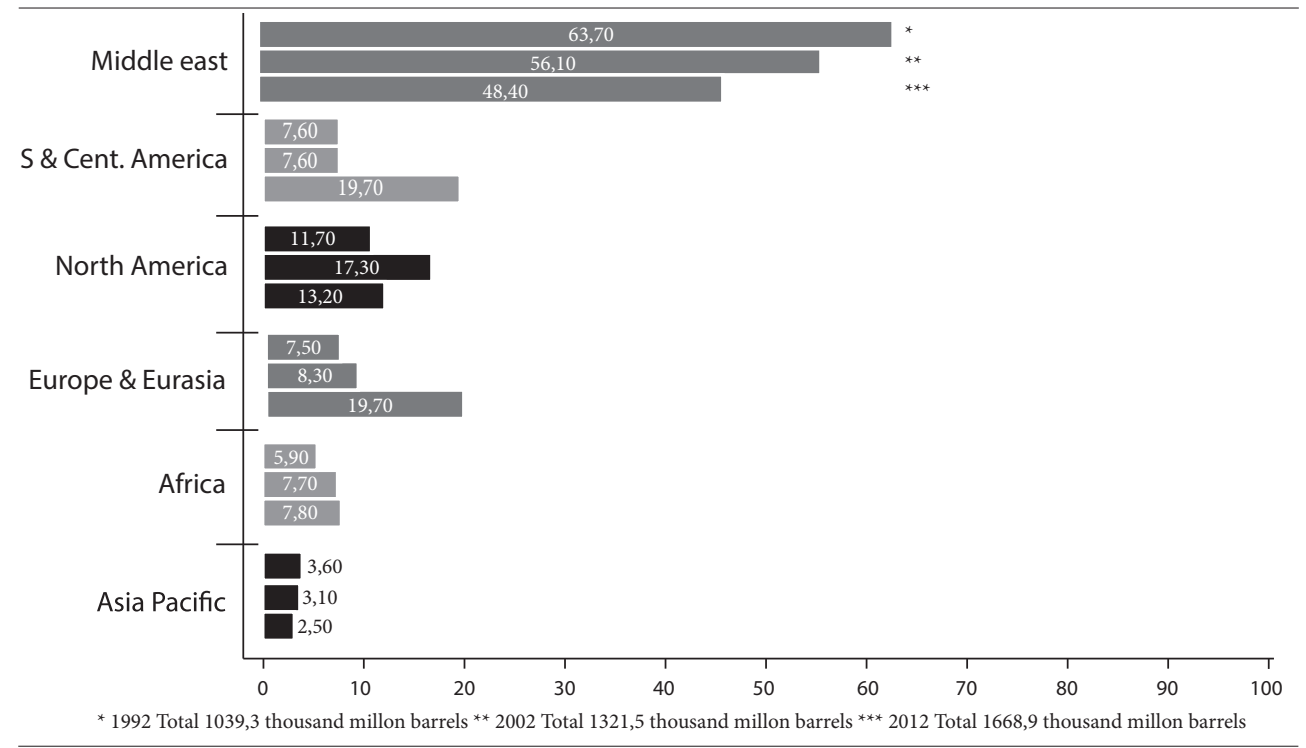

Fuente: Statistical Review of World Energy, 2013.

Figura 3. Evolución de las reservas probadas de gas natural del mundo entre 1992 y 2012. Datos expresados en porcentaje (\%) por región.

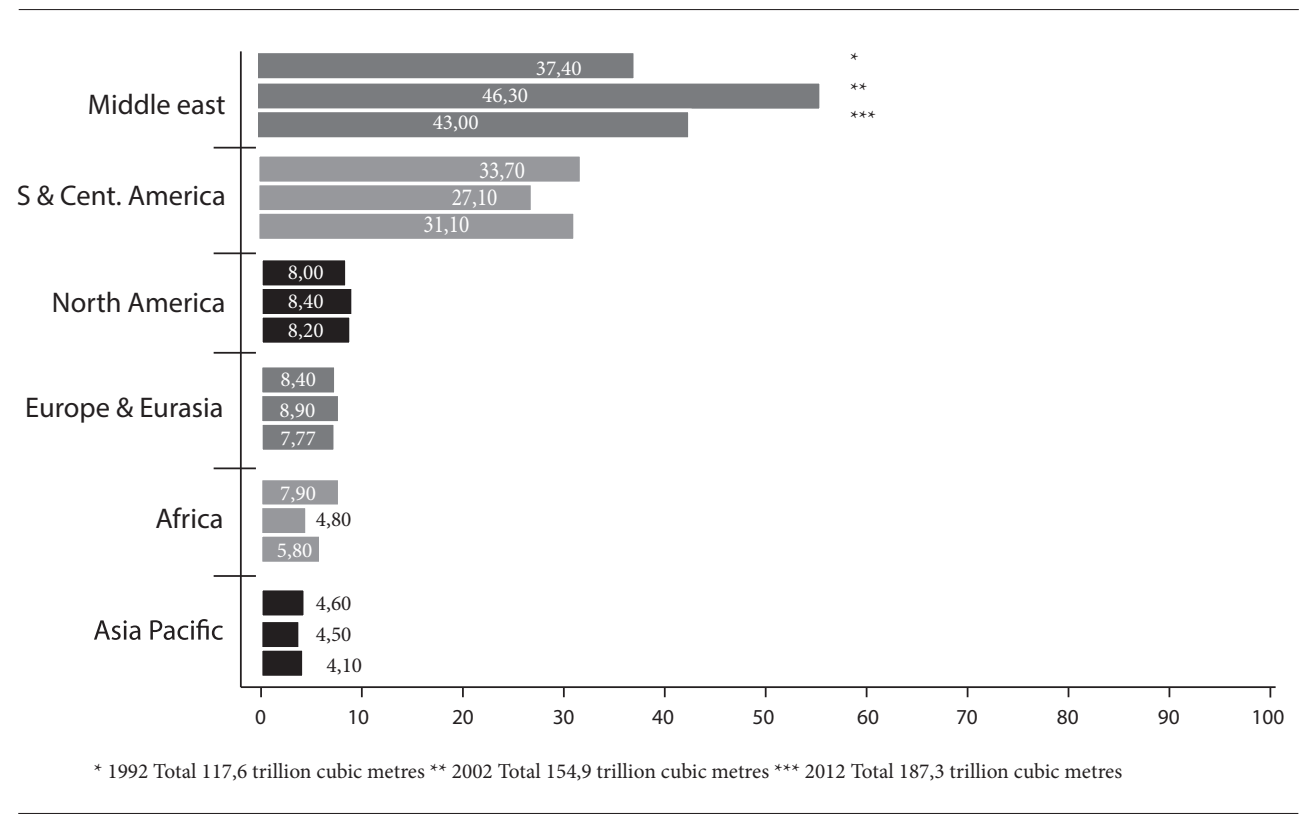

Fuente: Statistical Review of World Energy, 2013. 
Figura 4. Evolución de las reservas probadas de carbón del mundo entre 1992 y 2012. Datos expresados en porcentaje (\%) por región.

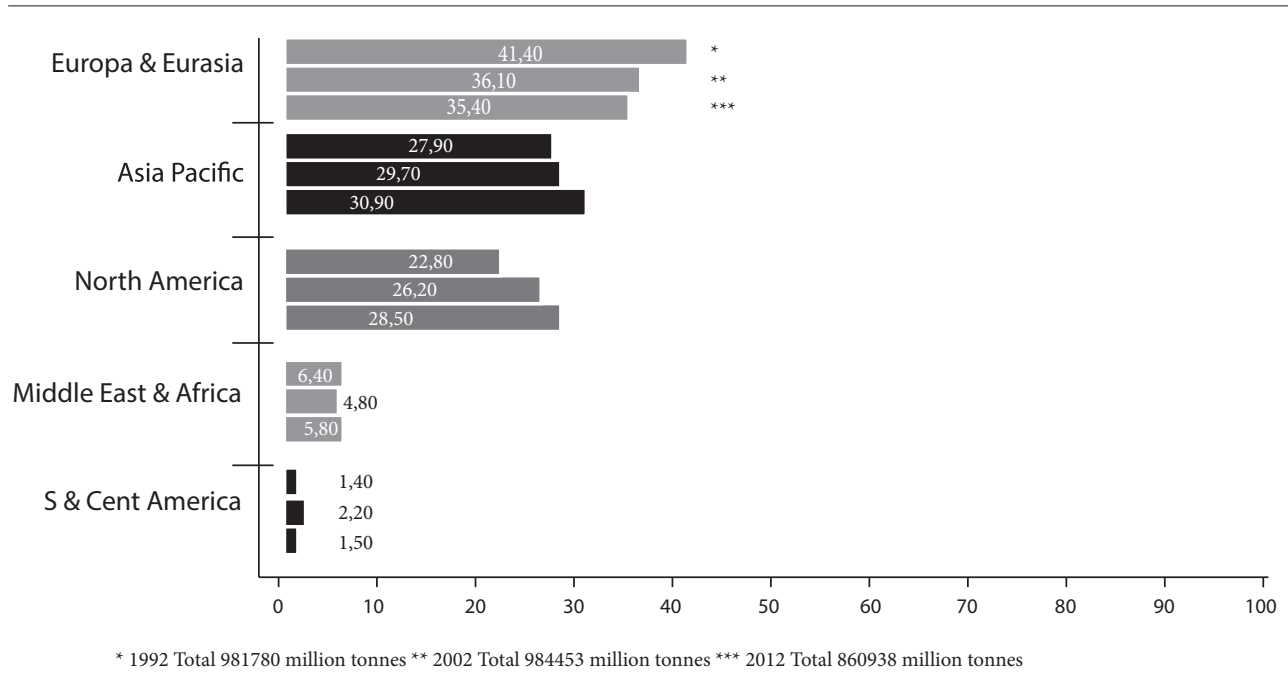

Fuente: Statistical Review of World Energy, (2013).

Tabla 1. Distribución de las reservas probadas de petróleo en América Latina.

\begin{tabular}{lcc}
\hline \multicolumn{1}{c}{ PAÍsES } & MILES DE MILLONES DE BARRILES & \% RESPECTO A LAS RESERVAS DEL MUNDO \\
\hline Argentina & 2,50 & 0,20 \\
Brasil & 15,30 & 0,90 \\
Colombia & 2,20 & 0,10 \\
Ecuador & 8,20 & 0,50 \\
Perú & 1,20 & 0,10 \\
Venezuela & 297,60 & 17,80 \\
Resto América Latina & 1,30 & 0,10 \\
Total América Latina & 328,30 & 19,70 \\
\hline
\end{tabular}

Fuente: Statistical Review of World Energy, (2013). Elaboración: propia. Nota: El estudio citado excluye las reservas de México del resto de la región.

Latina y el Caribe alcanzó un nuevo máximo de 188.101 millones de dólares, monto que supera por un 6\% el registrado en 2012» (CEPAL, 2012; 2013; 2014, p. 9) (ver Figura 5).

La gran reserva de recursos naturales que posee América Latina es el detonante para el extraordinario crecimiento de inversión directa en la región, especialmente en los últimos años. Durante el período 1990-2009, la inversión en recursos naturales alcanzó los 7342 millones de dólares mientras que en el 2010 fue de 13712 millones de dólares; es decir, el doble de lo que se obtuvo en diecinueve años. En los años 2011 y 2012, se produce una reducción pero el monto aún sigue siendo importante (CEPAL, 2012). Durante el año 
Figura 5. Entradas de inversión extranjera directa entre 1990 y 2013 en América Latina y el Caribe.

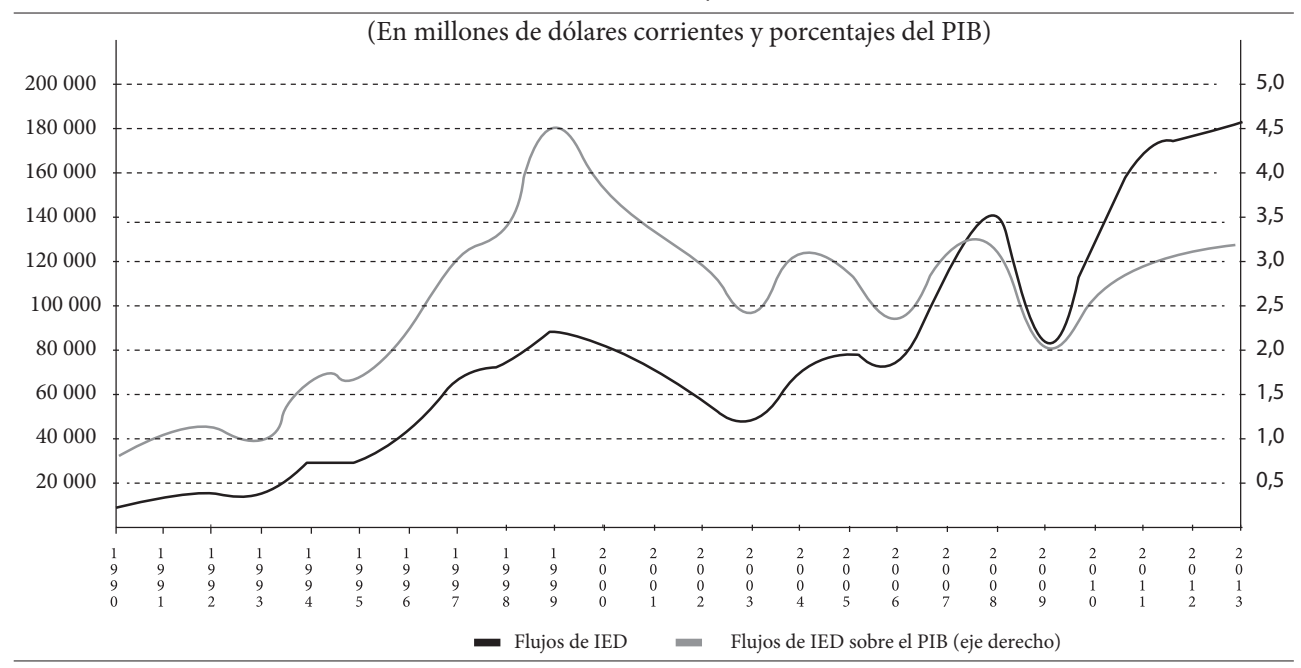

Fuente: CEPAL (2014, pág. 9).

Figura 6. Evolución de la IED de China en el exterior entre 1990 y 2012 (en millones de dólares).

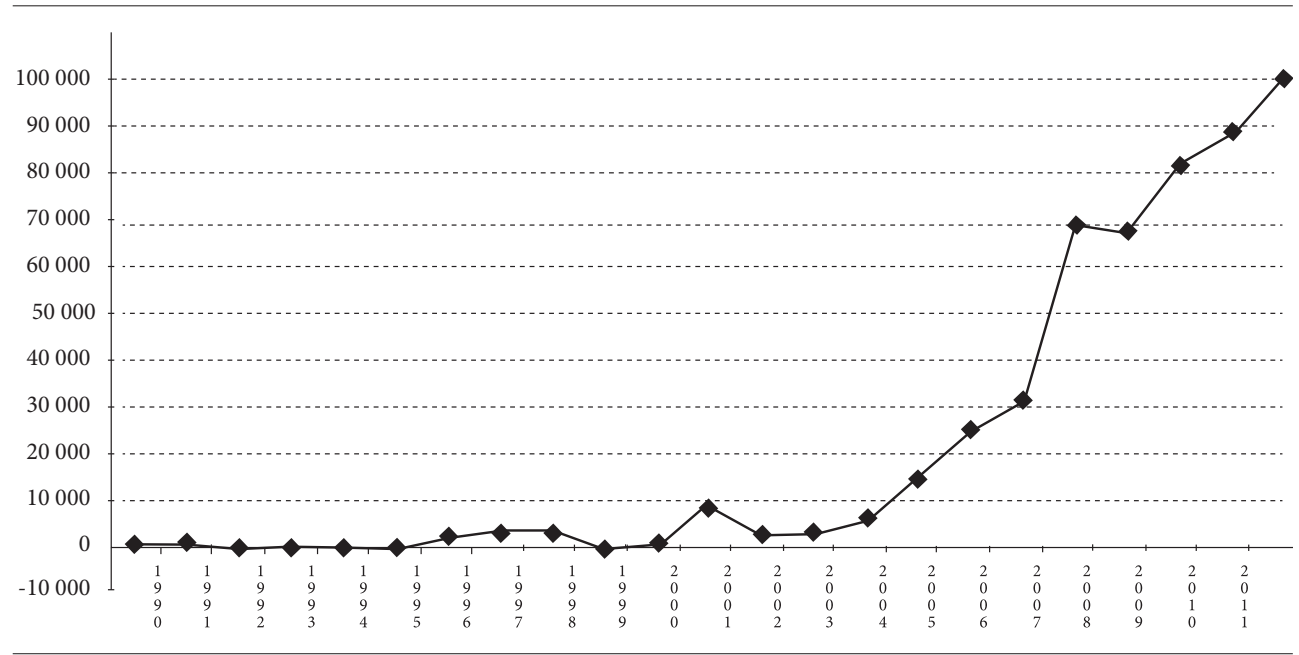

Fuente: UNCTAD (2013).

2013, la inversión en recursos naturales representó el 26\% de la inversión total en la región (CEPAL, 2014, p. 6). La evolución de la IED de China fue muy baja hasta el año 2004; después de este año el ritmo de crecimiento se aceleró debido a las políticas de apertura al exterior (ver Figura 6). 
Tabla 2. América Latina y el Caribe: Ingresos de inversión extranjera directa por sector recursos naturales, 1990-2009 (en millones de dólares).

\begin{tabular}{lcccc}
\hline \multicolumn{1}{c}{ PAÍsES } & $1990-2009$ & 2010 & 2011 & 2012 \\
\hline Argentina & 143 & 3100 & 2450 & 600 \\
Brasil & 255 & 9563 & 5676 & 6067 \\
Chile & $\mathrm{ND}$ & 5 & 0 & 76 \\
Colombia & 1677 & 6 & 293 & 996 \\
Ecuador & 1619 & 45 & 59 & 86 \\
Guyana & 1000 & $\mathrm{ND}$ & 15 & $\mathrm{ND}$ \\
México & 146 & 9 & 2 & 74 \\
Perú & 2262 & 84 & 829 & 1307 \\
Trinidad y Tobago & $\mathrm{ND}$ & $\mathrm{ND}$ & 850 & $\mathrm{ND}$ \\
Venezuela & 240 & 900 & $\mathrm{ND}$ & $\mathrm{ND}$ \\
TOTAL & 7342 & 13712 & 10174 & 9206 \\
\hline
\end{tabular}

Fuente: CEPAL (2013).

Tabla 3. Distribución de los proyectos de China en América Latina, por sector. Periodo 2010-2012 (en \%).

\begin{tabular}{lcccccc}
\hline & AGRICULTURA & \multicolumn{5}{c}{ EXTRACCIÓN } \\
\hline \multicolumn{1}{c}{ CATEGORÍA I } & 2010 & $2011-2012$ & 2010 & $2011-2012$ & 2010 & $2011-2012$ \\
Bolivia & 29 & 0 & 64 & 70 & 0 & 0 \\
Guyana & 33 & $\ldots$ & 33 & $\ldots$ & $\ldots$ & $\ldots$ \\
Ecuador & 6 & 0 & 13 & 17 & 19 & 25 \\
Venezuela & 8 & 5 & 8 & 26 & 17 & 42 \\
Perú & 4 & 7 & 35 & 43 & 4 & 7 \\
$\quad$ CATEGORÍA II & & & & & & \\
Brasil & 3 & 6 & 5 & 6 & 1 & 8 \\
Chile & 0 & 0 & 8 & 38 & 0 & 13 \\
México & 0 & 0 & 16 & 27 & 0 & 0 \\
Argentina & 5 & 30 & 22 & 20 & 0 & 10 \\
Colombia & 0 & 0 & 10 & 23 & 10 & 23 \\
Cuba & 0 & 0 & 0 & 33 & 0 & 0 \\
\hline
\end{tabular}

Fuente: Yue (2012). 
Tabla 3. Distribución de los proyectos de China en América Latina, por sector. (Periodo 2010-2012).

\begin{tabular}{lcccccc}
\hline & MANUFACTURA & \multicolumn{5}{c}{ COMERCIO } \\
\hline \multicolumn{1}{c}{ CATEGORIA I } & 2010 & $2011-2012$ & 2010 & $2011-2012$ & 2010 & $2011-2012$ \\
Bolivia & 0 & 0 & 0 & 10 & 0 & 0 \\
Guyana & 0 & $\ldots$ & 0 & $\ldots$ & 33 & $\ldots$ \\
Ecuador & 13 & 17 & 6 & 0 & 0 & 25 \\
Venezuela & 13 & 0 & 4 & 5 & 0 & 16 \\
Perú & 4 & 7 & 23 & 7 & 0 & 29 \\
$\quad$ CATEGORIA II & & & & & & \\
Brasil & 20 & 8 & 44 & 38 & 3 & 16 \\
Chile & 2 & 0 & 54 & 31 & 0 & 13 \\
México & 29 & 32 & 31 & 23 & 2 & 18 \\
Argentina & 16 & 0 & 27 & 0 & 8 & 30 \\
Colombia & 14 & 0 & 38 & 23 & 5 & 8 \\
Cuba & 15 & 0 & 10 & 0 & 10 & 67 \\
\hline
\end{tabular}

Fuente: Yue (2012).

Así, China pasa de 0,45\% de la IED mundial emitida en 2003 a 5,1\% en 2009, convirtiéndose en el país en desarrollo con mayor inversión y el quinto inversor absoluto tras Estados Unidos, Francia, Japón y Alemania. [...] En 2010, los principales destinos geográficos fueron Asia (76\% del stock de IED emitido por China) y Latinoamérica (12\%), quedando EE.UU y la Unión Europea como destinos minoritarios. (Oficina Económica y Comercial de España en Pekín, 2012, p. 31).

La motivación que ha encontrado China para invertir en Asia son los bajos costos laborales y el tamaño de mercado, mientras que en América Latina son los recursos energéticos y minerales. Según el Ministerio de Comercio de China, citado en Yue (2012), de los 14132 proyectos de China en el exterior durante el 2010,623 se dirigieron a América Latina y 221 a paraísos fiscales como las Islas Caimán y las Islas Vírgenes Británicas. La tendencia de focalización de la IED es hacia los países con grandes reservas de petróleo y minerales como Bolivia, Ecuador y Venezuela mientras que en países como Brasil, Colombia y México, el sector de comercio es el más atractivo.

Lin Yue (2012) clasifica la distribución geográfica e industrial de los proyectos de China en dos categorías; en la categoría I se encuentran los países de Bolivia, Guyana, Ecuador, Venezuela y Perú cuyo centro de captación de inversión china es el sector de extracción. Por ejemplo, del total de proyectos ejecutados en Bolivia en el sector de extracción durante el 2010, el 64\% corresponde a capitales chinos mientras que el 2011-2012 aumentó al 70\%. En Venezuela pasó del 8\% en el 2010 al 43\% en el periodo 2011-2012 (ver Tabla 2). Por su parte, en la categoría II se encuentran países como Brasil, Chile, México, Argentina, Colombia y Cuba donde la mayor cantidad de proyectos chinos se ubican en el sector de comercio (ver Tabla 
3). De esta forma, las inversiones realizadas por China durante el año 2010 en este campo representa en Brasil el 44\%, en Chile el 54\% y en Colombia el 38\% (Yue, 2012). Hay que señalar que durante el periodo 2011-2012 se ha reducido el porcentaje de proyectos con inversión china en el sector comercio.

\section{LA CONSOLIDACIÓN DE LAS EMPRESAS}

\section{EXTRACTIVAS CHINAS EN AMÉRICA LATINA}

En lo últimos años, empresas chinas públicas y/o privadas han adquirido los yacimientos más grandes de recursos no renovables de América Latina. Sin embargo, estos proyectos tienen un modelo de negocio común: han sido asignados de manera directa y cuentan con el financiamiento del gobierno chino, a través del Banco de Desarrollo de China.

En Venezuela, por ejemplo, la empresa estatal Corporación Nacional de Petróleo de China (CNCP) y la empresa estatal Petróleos de Venezuela (PDVSA) llevan a cabo alianzas estratégicas para explotar petróleo desde el 2006. Hasta el año 2010, CNCP controlaba aproximadamente 3 millones de toneladas de producción anuales, lo que representa alrededor del 5\% de su producción total de hidrocarburos (CEPAL, 2011). Perú es otro país donde China ha realizado grandes inversiones en recursos no renovables, como la industria minera, cuyos principales proyectos son: Toromocho y el Galeno. Del proyecto Toromocho «se esperan producir anualmente 250 mil toneladas de cobre (casi la cuarta parte de la producción total actual del país), además de molibdeno y plata. Del proyecto Galeno se espera producir 140 mil toneladas de cobre por año» (Revenue Watch Institute, 2012). Otras inversiones importantes en el Perú son las siderúrgicas estatales Shougang y Zijin. En este país se evidencia también un desplazamiento de las empresas tradicionales del sector minero - como las canadienses-, por empresas chinas. Por ejemplo, la empresa Zijin compró la compañía inglesa Monterrico; la empresa china Chinalco compró las acciones de la canadiense Perú Copper, concesionario de la propiedad Toromocho, que contiene uno de los depósitos más grandes de cobre del Perú. En el 2008, las empresas Minmetals y Jiangxi Copper adquirieron la canadiense Northern Perú Copper Corp. En territorio boliviano, China realiza inversiones en el sector petrolero y está interesado en la industrialización del litio del Salar de Uyuni en el cual ha invertido más de 400 millones de dólares para la fabricación de baterías.

Ecuador también es un país que ha hallado en China a uno de sus principales socios. El interés se encuentra principalmente en el sector de energía, exploración y explotación de petróleo y minerales - cobre y oro especialmente-. Sin embargo, existe interés en proyectos de construcción, proyectos hidroeléctricos, telecomunicaciones, productos forestales, productos agrícolas, agroindustriales, entre otros. «La inversión extranjera directa de China que se registra en el Banco Central del Ecuador ha sido significativa, es más, el país asiático es una de las principales fuentes de capital para Ecuador en los últimos cinco años» (Instituto de Promoción de Exportaciones e Inversiones PROECUADOR, 2012; en Loja y Torres, 2014, p. 19). En el sector petrolero, existe alianzas de cooperación estratégica entre Petroecuador (petrolera estatal ecuatoriana) y la empresa china Sinopec International Petroleum, para la exploración y explotación del Bloque 42 en la Amazonía ecuatoriana. Las empresas petroleras Petrochina y 
Tabla 4. Países latinoamericanos beneficiarios de préstamos de BM, BID y de China entre 2005 y 2011 (en millones USD).

\begin{tabular}{lcccc}
\hline \multicolumn{1}{c}{ PAÍs } & PREST. TOTALES & BANCO MUNDIAL & BID & CHINA \\
\hline Venezuela & 52.528 & - & 6.028 & 46.500 \\
Brasil & 39.628 & 15.338 & 12.559 & 11.731 \\
Argentina & 28.874 & 7.164 & 9.610 & 12.100 \\
México & 27.410 & 14.739 & 11.671 & 1.000 \\
Colombia & 12.118 & 6.241 & 5.877 & - \\
Ecuador & 9.864 & 153 & 2.457 & 7.254 \\
Perú & 6.113 & 3.045 & 2.868 & 200 \\
El Salvador & 2.954 & 1.196 & 1.758 & - \\
Guatemala & 2887 & 1.176 & 1.711 & - \\
Panamá & 2.811 & 591 & 2.220 & - \\
Costa Rica & 2.741 & 698 & 1.743 & 300 \\
República & 2.555 & 854 & 1.701 & - \\
Dominicana & 13.619 & 2169 & 6.730 & 4.720 \\
Otros & 204.102 & 53.364 & 66.933 & 83.805 \\
Total & & & & \\
\hline
\end{tabular}

Fuente: BM y BID, informes anuales. Tomado de Gallagher et al. (2013).

Tabla 5. Tasas de interés de los préstamos de Ex-Im Bank de China y de EE.UU.

\begin{tabular}{|c|c|c|c|c|}
\hline AÑO & PRESTAMISTA & PAÍS PRESTATARIO & PRESTATARIO & $\begin{array}{l}\text { TASA DE } \\
\text { INTERÉS }\end{array}$ \\
\hline 2007 & Ex-Im China & Jamaica & Gobierno & 2,00 \\
\hline 2009 & Ex-Im China & Bolivia & YPFB & 2,00 \\
\hline 2010 & Ex-Im China & Ecuador & Gobierno & 6,90 \\
\hline 2010 & Ex-Im China & Jamaica & Gobierno & 3,00 \\
\hline 2009 & Ex-Im EE. UU. & México & Pemex & 3,81 \\
\hline 2009 & Ex-Im EE. UU. & México & Eléctrica del valle de México & 4,30 \\
\hline 2009 & Ex-Im EE. UU. & Brasil & Logisitica MRS & 3,30 \\
\hline 2010 & Ex-Im EE. UU. & República Dominicana & Pueblo Viejo Dominicana & 4,02 \\
\hline 2010 & Ex-Im EE. UU. & Honduras & Energía Eólica de Honduras & 4,42 \\
\hline
\end{tabular}

Fuente: Informes anuales de Ex-Im Bank EEUU. Tomado de Gallagher et al. (2013). 
Tabla 5. Tasas de interés de los préstamos de Ex-Im Bank de China y de EE. UU.

\begin{tabular}{|c|c|c|c|c|}
\hline AÑO & $\begin{array}{c}\text { TASA MENOS LA } \\
\text { PRIMA DE RIESGO } \\
\text { DE LA OCDE }\end{array}$ & $\begin{array}{c}\text { MONTO } \\
\text { (MILLONES USD) }\end{array}$ & $\begin{array}{l}\text { PERÍODO } \\
\text { DE PAGO }\end{array}$ & PROPÓsITo \\
\hline 2007 & $-0,31$ & 45 & 20 & Centro de convenciones Montego Bay \\
\hline 2009 & $-0,31$ & 60 & 20 & $\begin{array}{l}\text { Instalaciones de Gas } \\
\text { domiciliario, perforaciones petroleras }\end{array}$ \\
\hline 2010 & 4,39 & 1,68 & 15 & Represa hidroeléctrica \\
\hline 2010 & 0,69 & 340 & 5 & Construcción vial \\
\hline 2009 & 2,04 & 600 & 10 & $\begin{array}{l}\text { Exploración petrolera y } \\
\text { equipo de producción }\end{array}$ \\
\hline 2009 & 2,53 & 81 & 4 & Turbinas eólicas Clipper Windpower \\
\hline 2009 & 1,53 & 87 & - & Locomotoras electro-diesel GE \\
\hline 2010 & 1,80 & 375 & - & $\begin{array}{l}\text { Camiones, excavadoras y } \\
\text { cargadoras Caterpilar }\end{array}$ \\
\hline 2010 & 2,11 & 159 & 18 & Turbinas eólicas Gamesa \\
\hline
\end{tabular}

Fuente: Informes anuales de Ex-Im Bank EEUU. Tomado de Gallagher et al. (2013).

Petroriental se encuentran también en negociaciones para la adjudicación de otros bloques petroleros. Mientras tanto, Andes Petroleum Co. opera en el Bloque Tarapoa 14 y 17 (Loja y Torres, 2014). Los contratos petroleros tienen una particularidad, pues están comprometidos por medio de grandes créditos que ha otorgado China al Ecuador.

El monto de deuda del Ecuador a China corresponde al 35,3\% de la deuda externa pública que sumó a mayo [de 2013] un total de \$12376 millones [...]. Según el estudio ¿Un mejor trato? Análisis comparativo de los préstamos chinos en América Latina del Instituto de Desarrollo Global y del Medioambiente de Tufts University y el Centro de Estudios China-México, Ecuador está en cuarto lugar en relación a los préstamos invertidos por la China en la región. El primer lugar lo ocupa Venezuela, seguido de Argentina y Brasil. (Diario Hoy, 11 de julio de 2013).

Los créditos implican acuerdos comerciales y financieros que implican dos asuntos: la venta anticipada de petróleo, y el canje de petróleo por deuda. En enero de 2015, Ecuador obtuvo un crédito adicional de 7526 millones de dólares para financiar proyectos sociales claves para el gobierno; sin embargo, no se conoce los términos de este nuevo crédito.

En cuanto a minería, el gobierno ecuatoriano suscribió el 5 de marzo del 2012 el contrato de explotación del proyecto «Mirador» con la compañía minera Ecuacorriente (ECSA), filial del consorcio chino Tongling Nonferrous Metals Group Holdings Co. Ltd. y China Railway Construction Corporation (CRCC). Este contrato prevé la explotación de cobre, oro y plata en la provincia de Zamora Chinchipe, con reservas por 5000 millones de libras de cobre. Otro proyecto perteneciente a este mismo consorcio es «Pananza - San Carlos», que al igual que «Mirador» también es considerado como proyecto estratégico y cuyo costo de inversión es de 1222 millones de dólares. 
Tabla 6. Préstamos chinos por petróleo en América Latina.

\begin{tabular}{|c|c|c|c|c|c|}
\hline AÑO & PAÍS PRESTATARIO & PRESTATARIO & PRESTAMISTA & $\begin{array}{c}\text { MONTO } \\
\text { (MILL. USD) }\end{array}$ & PROPÓSITO \\
\hline 2008 & Venezuela & $\begin{array}{l}\text { BANDES Y } \\
\text { PDVSA }\end{array}$ & $\mathrm{BDC}$ & 4000 & $\begin{array}{l}\text { Financiamiento de infraes- } \\
\text { tructura, otros proyectos }\end{array}$ \\
\hline 2009 & Brasil & Petrobras & $\mathrm{BD}$ & 10.000 & Tecnología petrolera presal \\
\hline 2009 & Ecuador & Petroecuador & Petrochina & 1000 & $\begin{array}{l}\text { Anticipo por el petró- } \\
\text { leo de Petroecuador }\end{array}$ \\
\hline 2009 & Venezuela & $\begin{array}{l}\text { BANDES Y } \\
\text { PDVSA }\end{array}$ & $\mathrm{BDC}$ & 4000 & $\begin{array}{l}\text { Infraestructura, in- } \\
\text { cluyendo satélite }\end{array}$ \\
\hline 2010 & Ecuador & Petroecuador & $\mathrm{BDC}$ & 1000 & $\begin{array}{l}80 \% \text { discrecional, } 20 \% \text { re- } \\
\text { lacionado con petróleo }\end{array}$ \\
\hline 2010 & Venezuela & $\begin{array}{l}\text { BANDES Y } \\
\text { PDVSA }\end{array}$ & $\mathrm{BDC}$ & 20.000 & $\begin{array}{l}\text { Financiamiento para } \\
\text { infraestructura }\end{array}$ \\
\hline 2011 & Ecuador & Petroecuador & Petrochina & 1000 & $\begin{array}{l}\text { Anticipo por el petró- } \\
\text { leo de Petroecuador }\end{array}$ \\
\hline 2011 & Ecuador & Gobierno & $\mathrm{BDC}$ & 2000 & $\begin{array}{l}70 \% \text { discrecional, } 30 \% \text { re- } \\
\text { lacionado con petróleo }\end{array}$ \\
\hline 2011 & Venezuela & PDVSA & $\mathrm{BDC}$ & 4000 & Infraestructura \\
\hline 2011 & Venezuela & PDVSA & ICBC & 4000 & Vivienda \\
\hline 2012 & Venezuela & $\begin{array}{l}\text { BANDES Y } \\
\text { PDVSA }\end{array}$ & $\mathrm{BDC}$ & 8000 & $\begin{array}{l}\text { Infraestructura, industria, } \\
\text { agricultura, minería, energía }\end{array}$ \\
\hline
\end{tabular}

Fuente: Gallagher et al. (2013).

Inicialmente, los proyectos cupríferos «Mirador» y «Pananza - San Carlos» estaban a cargo de la empresa canadiense Corriente Resources; sin embargo, en junio de 2010, el consorcio chino Tongling Metals y CRCC adquirió el 96,9\% de la minera canadiense y los proyectos de cobre antes mencionados (Sacher y Acosta, 2012). En el Azuay, el proyecto minero «Rio Blanco» pasó de la empresa canadiense International Minerals Corporation (IMC) a la empresa china Junefield para continuar con los estudios de exploración avanzada.

En resumen, existe una agresiva intromisión de empresas chinas en el sector extractivo latinoamericano que trae como consecuencia inmediata el desplazamiento de proyectos de menor envergadura y la proliferación de inversiones bajo el condicionamiento de préstamos chinos a los países de América Latina. No obstante, también es notorio que las políticas de cada nación favorecen la ampliación de las fronteras extractivas, pues ven en la extracción de recursos naturales el respaldo perfecto para conseguir nuevos créditos e inversiones para sus Estados. 


\section{FINANCIAMIENTO CHINO EN PAÍSES DE AMÉRICA LATINA RESPALDADO POR COMMODITIES}

La economía de China es, después de la de Estados Unidos, la más grande por su mercado potencial y su creciente demanda. Los acercamientos con América Latina datan desde 1560 «cuando se estableció la ruta de la seda» hasta 1815 (Shixue, 2006, p. 62). Las relaciones de América Latina con China se vieron afectadas por el nuevo orden mundial establecido después de la segunda guerra, en el cual Estados Unidos se posiciona como potencia conjuntamente con sus aliados franceses e ingleses. A pesar de ello, en los años 60 se funda la «Asociación de amistad entre China y América Latina (AACAL)» (Shixue, 2006, p. 63). Estos acercamientos permitieron al país asiático mantener una relación fluída con la región no solo como socio estrategico sino tambien como prestasmista. «China ha intentado unirse al Banco Interamericano de Desarrollo principal fuente multilateral de financiamiento para América Latina» (Shixue, 2006); sin embargo, esta iniciativa fue objetada por Estados Unidos. Mas allá de los argumentos que EE. UU. pueda plantear, está claro que aunque América Latina no esté en la agenda principal de Norteamérica no dejará que otra potencia emergente tenga acceso a los recursos de Latinoamérica.

No obstante, la estrategia de China en América Latina está teniendo resultados, llegando al punto de generar un desplazamiento a los prestamistas tradicionales. Entre 2005 y 2011, los préstamos chinos a América Latina ascendieron a 83000 millones de dólares (ver Tabla 4), siendo ampliamente mayor que el otorgado por otros organismos crediticios como el Banco Mundial o el Banco Interamericano de Desarrollo. Aunque este financiamiento tiene algunas ventajas, algunos paquetes de inversión tienen condiciones diferentes a las occidentales, pues no están dirigidas a un sector estratégico (Gallaher et al., 2013); a pesar de ello, el financiamiento chino ha servido para la explotación primaria. Así mismo, Shixue (2006) escribe: «El rápido crecimiento de la economía china requiere un mayor ingreso de recursos naturales y materias primas y Latinoamérica en este sentido constituye un socio adecuado» (p. 71). De esta condición, China ha demandado del mundo gran cantidad de materias primas como oro, cobre, soja y petróleo. De forma detallada, a América Latina le ha llegado préstamos de China de la siguiente manera: $81 \%$ de los préstamos del Banco de Desarrollo Chino (BDC), 10\% del Banco de Exportaciones e Importaciones Chino (China Ex-Im Bank) y 6\% del Industrial and Comercial Bank of China (ICBC). De estos «Argentina, Brasil y Ecuador recibieron el 43\%. Además, el 79\% del total de préstamos fueron para petróleo» (Gallaher et al., 2013, p. 6). Algunos detalles de dichos préstamos, comparados con el Ex-Im Bank de EEUU se detallan en la Tabla 5.

Es curioso el hecho de que el $61 \%$ de los préstamos chinos se direccionaron para Ecuador y Venezuela, lo cual es entendible pues los préstamos fueron destinados a inversión petrolífera (ver Tabla 6). Aunque dichos créditos no se condicionan para uno u otro sector, es claro que hay una preferencia para la explotación de hidrocarburos. Hay otra explicación para este fenómeno: Las deudas de estos países a organismos como el BID o el Banco Mundial les ha dado una mala fama como países prestatarios, y los préstamos chinos son, a pesar de sus altas tasas, una salida al problema de financiamiento de sus presupuestos nacionales (Gallaher et al., 2013). De esto se desprenden los préstamos por petróleo, a los cuales Gallaher et al. se refiere: 
China ha utilizado sus préstamos por petróleo y sus exigencias de compra para reducir el riesgo de prestar a beneficiarios que de otra forma no serían solventes. En este sentido el fundador del $\mathrm{BDC}$ dijo que respaldar los préstamos con envíos de petróleo mantiene efectivamente los riesgos a un nivel mínimo. La mitigación del riesgo de los préstamos por petróleo parece explicar como el BDC pudo ofrecer el préstamo venezolano de USD 20 mil millones a un tipo flotante de 50-285 puntos básicos sobre la tasa Libor (Gallaher et al., 2013, p. 11).

Como ya se mencionó, la economía china se alimenta de cantidades ingentes de materias primas, y los préstamos respaldados con commodities son una manera de acceder a los recursos naturales regionales. Venezuela, Ecuador y Brasil mantienen préstamos con China, pero a cambio están supeditados a enviar petróleo al gigante asíatico al menos mientras la deuda sea subsanada, y cuyo criterio condicionante son las altas tasas de interés por los créditos, que, como en el caso del crédito del Ex-Im Bank China al Estado ecuatoriano, son de las tasas más altas del mundo.

\section{CONCLUSIONES}

América Latina se consolida como zona de amplio interés para los países industrializados gracias a sus reservas de recursos naturales. En este sentido, la región posee grandes reservas de minerales estratégicos que resultan indispensables para usos tecnológicos; así mismo, posee una cantidad considerable de las reservas probadas de petróleo a nivel mundial. Los actuales precios de los commodities, junto con las políticas populistas de varios gobiernos latinoamericanos, han desencadenado una profundización del modelo primario-exportador como sostén de las economías nacionales, llamado también «reprimarización de las economías». Este hecho está generando una continua ampliación de fronteras extractivas cuyos impactos sociales, culturales y ambientales podrían resultar irreversibles.

China, a través de la inversión extranjera directa, busca asegurar el abastecimiento de materias primas para su industria y nuevos mercados para sus productos. Los recursos naturales que posee América Latina le convierten en una región atractiva para el país asiático, muestra de ello es su evolución positiva de los flujos de inversión extranjera directa hacia esta región. Las inversiones chinas en los sectores de recursos naturales se encaminan a los países que poseen grandes reservas petroleras y mineras como Bolivia, Ecuador, Venezuela y Perú. Evidencia de ello es cómo las empresas estatales de China son las principales inversoras en recursos naturales en la región. Por otro lado, en países como Brasil, Chile, México o Colombia el sector del comercio les resulta más atractivo. Las cuantiosas inversiones chinas en América Latina, generan una nueva hegemonía sobre la región, pues dicho país asiático ha adquirido los principales depósitos de recursos naturales, principalmente los yacimientos cupríferos. Además, esta hegemonía se consolida con inversiones o créditos destinados a infraestructura tanto para proyectos hidroeléctricos, viales o para industrialización de los hidrocarburos.

Las exigencias ambientales de China para créditos externos presentan amplia flexibilidad en términos de protección de ecosistemas y se centran más bien en indicadores financieros, lo cual provocará que el financiamiento de ese país coadyuve a un mayor deterioro del patrimonio natural de América Latina. Así mismo, la región se verá obligada a sobreexplotar 
sus recursos para satisfacer sus necesidades internas y cumplir con sus obligaciones crediticias con capitales chinos. Los préstamos chinos son significativamente superiores a los préstamos otorgados por otros organismos internacionales de crédito, y estos en su mayoría son respaldados con commodities. En este sentido, los préstamos por petróleo son una estrategia crediticia china para los países con primas de riesgo relativamente altas, como Venezuela y Ecuador. Sin embargo, más allá del cuestionado «altruismo chino», América Latina es geopolíticamente interesante para el gigante asiático, y los préstamos por petróleo son una manera excepcional de tener el control o al menos una fuerte injerencia sobre los recursos latinoamericanos.

\section{REFERENCIAS}

Banco Interamericano de Desarrollo BID (2007). El surgimiento de China Oportunidades y Desafíos para América Latina y el Caribe. Santiago, Chile: (s/e).

Bárcena, A. (2013). Relaciones de comercio e inversión entre China y América Latina. Ponencia presentada en Seminario Haciendo negocios con China: Experiencias de América Latina. Santiago, Chile.

BP Statistical Review of World Energy (2013). Statistical Review of World Energy. BP. Recuperado de http://www. bp.com/content/dam/bp/pdf/statisticalreview/statistical_review_of_world_energy_2013.pdf_

Brautigam, D. (2011). Aid, With Chinese Caracteristics: Chinese Foreign Aid and Development Finance Meet the OECD-DAC Aid regime. Journal of International Development 23(25), s/p.

Bruckmann, M. (2012). Recursos Naturales y la Geopolítica de la Integración Sudamericana. Quito, Ecuador: Editorial IAEN.

CEPAL (2011). La inversión extranjera directa en América Latina y el Caribe 2010. Santiago, Chile: Comisión Económica para América Latina y el Caribe.

CEPAL (2012). La Inversión Extranjera Directa en América Latina y el Caribe, 2011. Santiago, Chile: Comisión Económica para América Latina y el Caribe.

CEPAL (2013). La Inversión Extranjera Directa en América Latina y el Caribe, 2012. Santiago, Chile: Comisión Económica para América Latina y el Caribe.

CEPAL (2014). La Inversión Extranjera Directa en América Latina y el Caribe, 2013. Santiago, Chile: Comisión Económica para América Latina y el Caribe.

Cisneros, P. (2011). ¿Cómo se construye la sustentabilidad? Experiencias conflictivas de la industria minera en Ecuador. Quito, Ecuador: FLACSO Sede Ecuador.

Downs, E. (2011). Inside China, Inc.: China Development Bank’s Cross-Border Energy Deals. En Hacia una nueva agenda en inversión extranjera directa: tendencias y realidades en América Latina (s/p). Banco de Desarrollo de América Latina (CAF), Serie Políticas Públicas y Transformación Productiva N.o 10/2013.

Flavin, Ch. y Gardner G. (2006). China, la India y el nuevo orden mundial. En World Watch Institute (Eds.) La situación del mundo 2006. Barcelona, España: Icaria.

Gallagher, K., Amos, I. y Koleski, K. (2013). ¿Un mejor trato? Análisis comparativo de los préstamos chinos en América Latina. México DF., México: Universidad Nacional Autónoma de México. 
La deuda con China en este año sumarán $\$ 8177$ millones. (2013, julio 11). Diario Hoy. Recuperado de http://www.hoy. com.ec/noticias-ecuador/la-deuda-con-china-este-ano-sumara-8-177-millones-585690.html

Oficina Económica y Comercial de España en Pekín (2012). Informe Comercial y Económico de China. Pekín, China.

OPEP (2013). Annual Statistical Bulletin. Vienna: Organization of the Petroleum Exporting Countries. PROECUADOR, Instituto de Promoción de Exportaciones e Inversiones (2012). Ficha comercial de China. Dirección de Inteligencia Comercial e Inversiones. En L. Loja y N. Torres, La inversión extranjera directa en el Ecuador durante el periodo 1979-2011: Análisis de su incidencia en el crecimiento económico (s/p).

Revenue Wacht Institute (2012). Reporte anual de tendencias de las industrias extractivas en América Latina 2011. Fundar, Centro de Análisis e Investigación. Recuperado de http://www.fundar.org. $\mathrm{mx} / \mathrm{mexico/pdf/tdlaie.pdf}$

Sacher, W. y Acosta, A. (2012). La minería a gran escala en Ecuador. Quito, Ecuador: Abya-Yala.

Sesarin, S. y Moneta, C. (2005). China y América Latina.Nuevos enfoques sobre cooperación y desarrollo ¿Una segunda ruta de la seda?. Buenos Aires, Argentina: BID-INTAL.

Shixue, J. (2006). Una mirada china a las relaciones con América Latina. Nueva Sociedad, (203), 62-68. Total and urban population, annual, 1950-2050. (s.f.). UNCTAD (United Nations Conference on trade and development). Recuperado de http://unctadstat.unctad.org/TableViewer/tableView. aspx?ReportId $=88$

Yue, L. (2012). Inversión extranjera directa de China en América Latina. Madrid, España: Centro de Estudios de Asia Oriental, Universidad Autónoma de Madrid. 
